\title{
PENGEMBANGAN PEMASARAN USAHA BAKERY AICA PCA KEDUNGKANDANG MALANG
}

\author{
Fika Fitriasari $^{1}$, Titiek Ambarwati ${ }^{2}$ \\ Universitas Muhammadiyah Malang ${ }^{1,2}$
}

\begin{abstract}
AICA PCA Kedungkandan Malang was established in 2017. AICA produces various bakeries that have a large market opportunity in the Malang area. In the future, this business can develop quite rapidly with various potentials owned by AICA Bakery, one of the characteristics of AICA products is that all ingredients used are halal and natural. The problems experienced by Bakery AICA are that marketing management is not yet optimal, there is no development of Human Resources management, and there is no ongoing assistance in business development. The results of this AICA bakery service development activity improve business management skills that are more professional starting from human resource management and marketing management. Bakery marketing is expanded by using social media and human resources or production department employees are added, so that AICA Bakery becomes a more productive business. Through the AICA PCA Kedungkandang Bakery mentoring program in the long run it can provide economic added value to the Muhammadiyah's charitable endeavors.
\end{abstract}

Keywords: Bakery; AICA; Business

\section{Abstrak}

Bakery AICA Pimpinan Cabang Aisyiyah Kedungkandang Malang didirikan pada tahun 2017. AICA memproduksi aneka bakery mempunyai peluang pasar yang besar di daerah Malang. Usaha ini kedepannya dapat berkembang cukup pesat dengan berbagai potensi yang dimiliki Bakery AICA, salah satu ciri khas produk AICA adalah semua bahan yang digunakan halal dan alami. Permasalahan yang dialami oleh Bakery AICA adalah belum optimalnya manajemen Pemasaran, belum adanya pengembangan manajemen Sumber Daya Manusia, dan belum adanya pendampingan berkelanjutan dalam pengembangan usaha. Hasil Kegiatan Pengabdian pengembangan bakery AICA ini meningkatkan ketrampilan pengelolaan manajemen usaha yang lebih professional mulai pengelolaan manajemen sumberdaya manusia dan manajemen pemasaran. Pemasaran bakery diperluas dengan menggunakan media sosial dan sumber daya manusia atau karyawan bagian produksi ditambah, sehingga Bakery AICA menjadi usaha yang lebih produktif. Melalui program pendampingan Bakery AICA PCA Kedungkandang dalam jangka panjang dapat memberikan nilai tambah ekonomi bagi amal usaha Muhammadiyah tersebut.

Kata Kunci: Bakery; AICA; Usaha

\section{PENDAHULUAN}

Pengembangan usaha kecil dan menengah (UKM) sebagai basis ekonomi kerakyatan adalah strategi yang perlu dilaksanakan dengan langkah nyata (Afridhal, 2017; Aini \& Rifani, 2015). UKM yang memproduksi roti (bakery) pada saat ini ramai semakin dilirik orang. Salah satu masalah yang dihadapi usaha bakery adalah bagaimana cara pengembangan usaha. Akan tetapi dalam perkembangan suatu usaha tentu diperlukan pengembangan dan peningkatan, sehingga harus dirumuskan strategi pengembangan usaha yang tepat agar tujuan bisnis tersebut dapat tercapai (Nurdin, 2017).

Persaingan yang semakin ketat dalam usaha makanan akan mendorong munculnya strategi untuk mempertahankan usahnya. Usaha roti atau bakery merupakan usaha yang masih terus bertahan ditengah ketatnya persaingan usaha dagang (Dwikurnia, 2016; Khikmawati, 2018). Masalah yang sering dihadapi industry kecil atau industry rumahan adalah bagaimana mengembangkan strategi bisnisnya. Usaha atau bisnis identik dengan adanya kesiapan strategi pemasaran yang kuat dan ketepatan melihat potensi pasar. Pada saat produk diluncurkan ke pasar, maka bias dikatakan produk tersebut adalah hasil kematangan dari suatu konsep pemasaran (Lang et al., 2015; Yola, 2019).

Aisyiyah adalah salah satu organisasi ortonom perempuan yang berada di bawah Persyarikatan Muhammadiyah. 'Aisyiyah merupakan pergerakan perempuan Persyarikatan Muhammadiyah telah memberikan corak tersendiri dalam ranah keagamaan, pendidikan, sosial, dan kesehatan yang selama ini menjadi fokus pergerakannya. Gerakan 'Aisyiyah semakin hari terus berkembang serta memberikan manfaat bagi peningkatan dan kemajuan harkat dan martabat perempuan di Indonesia. Hasil yang sangat

1 fika@umm.ac.id. 
nyata adalah wujud amal usaha yang terdiri atas ribuan taman kanak-kanak, sekolah dasar, hingga perguruan tinggi. Salah satunya adalah Pimpinan Cabang Aisyiyah Kedungkandang yang memiliki beberapa amal usaha. Salah satu usaha yang sedang berkembang dan memiliki potensi untuk jadi besar adalah Bakery AICA yang memproduksi berbagai macam roti.

Bakery AICA PCA Kedungkandang Malang diresmikan pada tahun 2017, bergerak di bidang pangan yaitu memproduksi roti. Bakery AICA telah memiliki surat ijin pendirian usaha dan dalam proses untuk mengurus sertifikat halal. Bakery AICA PCA Kedungkandang ini mempunyai peluang yang sangat besar di pasaran karena banyak orang yang menyukai roti. Bakery AICA memiliki rasa yang enak sehingga usaha ini kedepannya dapat berkembang cukup pesat. Roti di negara Indonesia merupakan makanan yang dapat digunakan untuk mengganti makanan pokok atau nasi. Sehingga dapat dimakan ketika sarapan, makan siang ataupun makan malam. Roti AICA juga dapat digunakan untuk acara-acara formal ataupun informal, baik acara kuliah tamu, acara rapat, dll. Roti yang berasal dari tepung dan bahan campuran lainnya melalui proses pengovenan memiliki daya tahan lebih tinggi daripada roti basah, sehingga dapat disimpan untuk sehari atau lebih. Roti digemari oleh berbagai kalangan, baik anak-anak, remaja hingga orang dewasa. Roti AICA ini tidak menggunakan bahan pengawet namun dapat bertahan 5 hari.

Berdasarkan hasil survey lapang tim pengabdian masyarakat kepada mitra usaha (AICA). Bakery AICA ini harus meningkatkan kemampuan ketrampilan yang telah dimiliki untuk berinovasi memperbanyak jumlah varian roti, serta mampu meningkatkan akses pasar yang luas sehingga dengan pelatihan dan pendampingan yang akan dilakukan menjadi kegiatan bersama antara mitra dengan tim pengabdian. Masalah Mitra (AICA) meliputi: a. Belum adanya bimbingan manajemen Pemasaran dan pendampingan berkelanjutan dalam pengembangan usaha. $b$. Belum adanya pengembangan dan penambahan SDM.

Tujuan dari pengabdian ini adalah untuk meningkatkan volume pemasaran dan memperluas jaringan pasar Bakery AICA, serta untuk meningkatkan kemampuan ketrampilan SDM yang telah dimiliki untuk berinovasi memperbanyak jumlah varian roti. Manfaat yang diperoleh oleh Mitra (Bakery AICA) Dalam Kegiatan Pengabdian masyarakat melalui program pendampingan Bakery AICA PCA Kedungkandang Malang diharapkan dalam jangka panjang dapat memberikan nilai tambah ekonomi bagi amal usaha Muhammadiyah, sehingga menjadi usaha produktif yang dapat meningkatkan pendapatan di Bakery AICA dan meningkatkan pendapatan PCA Kedungkandang Malang.

\section{MATERI DAN METODE PELAKSANAAN}

Pastry berasal dari kata paste yang mempunyai arti campuran antara cairan, terigu, dan lemak. Pembuatan pastry mengacu pada berbagai adonan seperti paste, dough, dan berbagai macam produk turunannya.Produk pastry ada yang menggunakan ragi dan ada juga yang tidak menggunakan ragi. Pada umumnya produk pastry bertekstur crispy (tidak kalis), akan tetapi beberapa produk pastry membutuhkan adonan yang kalis saat diroll seperti croissant, danish pastry, puff pastry (Azelia, 2015). Bakery adalah bagian dari pastry yang bertanggung jawab pada pembuatan roti, croissant, danish, dan produk yang lain dan disajikan setelah proses baking atau di oven. Setelah proses cooking pada bakery masih diperlukan penanganan lagi seperti memberi rasa dan tampilan sesuai dengan keperluan. Menurut U.S. Wheat Associated (1981) dalam Kraus (2004) : "Roti adalah produk pangan olahan yang merupakan hasil proses pemanggangan adonan yang telah difermentasi". Roti memiliki beberapa klasifikasi tersendiri, yaitu sebagai berikut: Tea bread \& bund, Roti gandum putih, Roti gandum coklat. Bakery atau roti adalah salah satu alternatif makanan yang diminati masyarakat karena praktis penyajiannya , tersedia aneka pilihan rasa, dan dapat dinikmati semua kalangan mulai anak-anak sampai orang tua (Dewi, 2015).

Dalam Kegiatan Pengabdian masyarakat melalui program pendampingan Bakery AICA PCA Kedungkandang Malang diharapkan dalam jangka panjang dapat memberikan nilai tambah ekonomi bagi amal usaha Muhammadiyah, sehingga menjadi usaha produktif yang dapat meningkatkan pendapatan di Bakery AICA dan meningkatkan pendapatan PCA Kedungkandang Malang. Luaran program pendampingan Bakery AICA PCA Kedungkandang Malang ini adalah pengembangan pemasaran dan SDM, pendampingan pendaftaran P-IRT, dan Publikasi Ilmiah. Kerangka Pemecahan masalah terdiri dari Bahan Baku, Produksi dan Nilai Investasi, Proses Produksi, Manajemen SDM dan Pemasaran. 


\section{Bahan baku.}

Bahan baku utama pembuatan roti basah adalah tepung, gula, telur, mentega, susu milk, dan bahan pendukung lainnya. Setiap hari dan setiap minggu kebutuhan bahan baku di suplai dari pembelian di toko bahan kue Prima Rasa, Diva, Jaya atau Candra. Kualitas bahan baku yang tinggi digunakan dalam pembuatan roti AICA agar roti yang dihasilkan kualitas dan rasanya juga enak. Kualitas bahan baku yang tinggi, otomatis juga menyebabkan harga bahan baku yang lebih mahal. Akan tetapi AICA berkomitmen bahwa dengan investasi yang lebih tinggi pada penyediaan bahan baku kualitas, maka akan membuat hasil roti lebih enak dan diharapkan masyarakat semakin loyal terhadap produk AICA.

Pemasaran Roti AICA pada saat ini di wilayah kota Malang khususnya daerah Kedungkandang. Yang menjadi pelanggan tetap Roti AICA adalah Ibu- ibu aisyiyah. Penjualan dilakukan di outlet yang dimiliki serta menggunakan gerobak untuk dijual disekolah-sekolah dekat rumah produksi. Produk AICAsudah mulai digemari oleh konsumen karena memiliki cita rasa yang lezat. Selain itu produk AICA selalu fresh karena dibuat setiap hari dan halal dikonsumsi. Produk halal adalah hal penting untuk konsumen muslim untuk melakukan suatu keputusan pembelian (Yola, 2019). Bakery AICA juga sudah dipercaya untuk dijual pada acara-acara bazar yang diselenggarakan oleh Muhammadiyah ataupun acara Aisyiyah. Selain itu produk AICA juga banyak dipesan pada acara-acara formal maupun non formal seperti acara pernikahan, acara diklat, acara seminar, rapat, tasyakuran, PKK, kegiatan Aisyiyah, dan lain-lain.

\section{Produksi dan Nilai Investasi.}

Usaha Bakery AICA mulai dibentuk pada tahun 2017 dengan modal awal sejumlah sepuluh juta rupiah. Seiring dengan perkembangan waktu nilai investasi yang ditanamkan pada usaha Bakery AICA semakin meningkat. Adanya penambahan produk baru, dan juga perluasan pemasaran membuat Bakery AICA semakin dikenal dari berbagai kalangan. Pada tahun 2018 ini rata-rata kas bersih Bakery AICA ini berkisar diantara 3-4 juta.

Kapasitas produksi usaha Bakery AICA ini masih terbatas, dikarenakan jumlah tenaga produksi hanya 4 orang dan hanya berproduksi sesuai dengan pesanan atau ada kegiatan tertentu milik Aisyiyah. Dengan jumlah karyawan sebanyak 4 orang, rata-rata kapasitas produksi berkisar antara 300500 roti sekali produksi. Jika pesanan melebihi kapasitas produksi, maka pihak AICA akan menolak pesanan tersebut. Dikarenakan minimnya jumlah tenaga produksi dan peralatan produksi yang ada.

\section{Proses produksi.}

Tempat proses produksi atau pembuatan Bakery AICA ini harus selalu dalam keadaan bersih dan higenis. Agar pembuatan roti tidak terhambat dengan keadaan setempat. Selain itu tempat juga menjadi cerminan dalam pembuatan roti-roti tersebut, karena jika tempat pembuatan roti tidak bersih otomatis roti yang dibuat akan dapat mengurangi rasa dari roti tersebut. Sehingga tempat produksi roti tersebut harus bersih, higienis dan mempunyai sanitasi yang baik. Dan roti yang dihasilkan pun dapat masak dengan benar dan jauh dari asumsi negatif dari tempat yang tidak bersih. Berikut gambar tempat produksi usaha AICA:

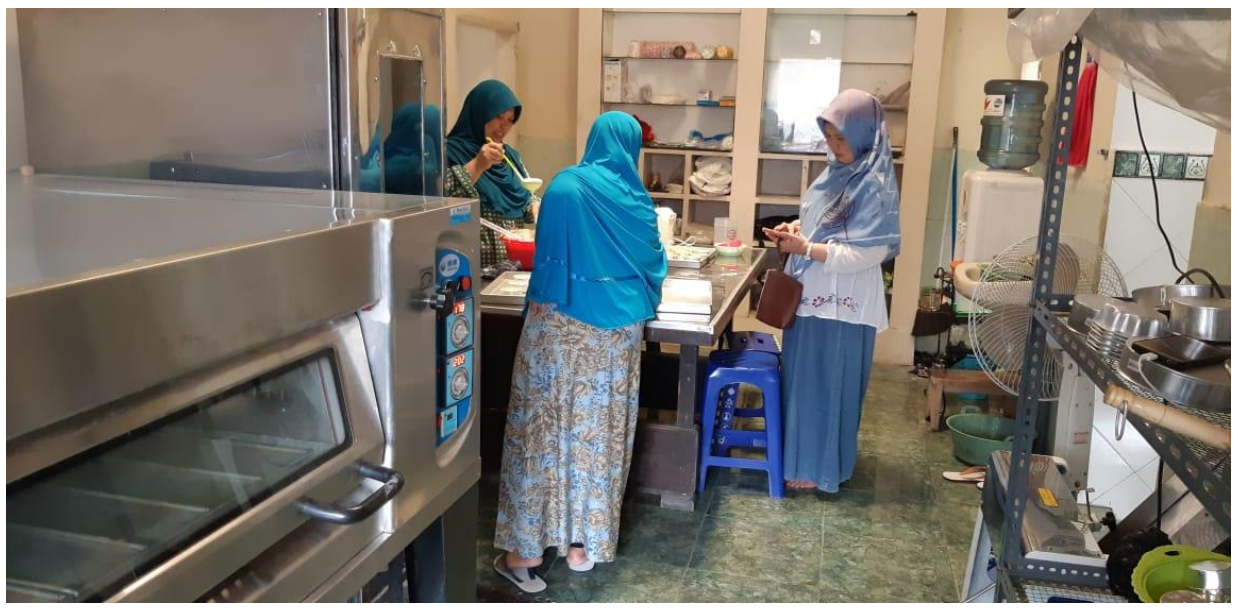

Gambar 1. Tempat Produksi Bakery AICA 
Adapun peralatan produksi yang dibutuh dalam proses pembuatan roti antara lain : 1. Mixer. Untuk mengaduk bahan-bahan roti 2. Pencetak roti 3. Penggorengan 4. Oven. Untuk memanggang roti 5. Baskom, sendok, pisau dan lainnya 6. Gelas ukur. Untuk mengukur takaran bahan roti 7. Timbangan. Untuk menimbang bahan roti 8. Kompor 9. Dan lain sebagainya Sumber bahan baku dari pembuatan Bakery AICA ini sangat mudah diperoleh diberbagai pusat perbelanjaan seperti pasar, supermarket, dan yang menjadi pemasok utama Bakery AICA ini adalah Toko bahan kue di Malang. Bahan pembuat roti antara lain : 1. Tepung 2. Telur 3. Gula 4. Bahan isian 5. Garam 6. Baking podwer 7. Fanily 8. Pewarna, dan penyedap lainnya. Diagram atau bagan alir proses produksi Bakery AICA adalah sebagai berikut:

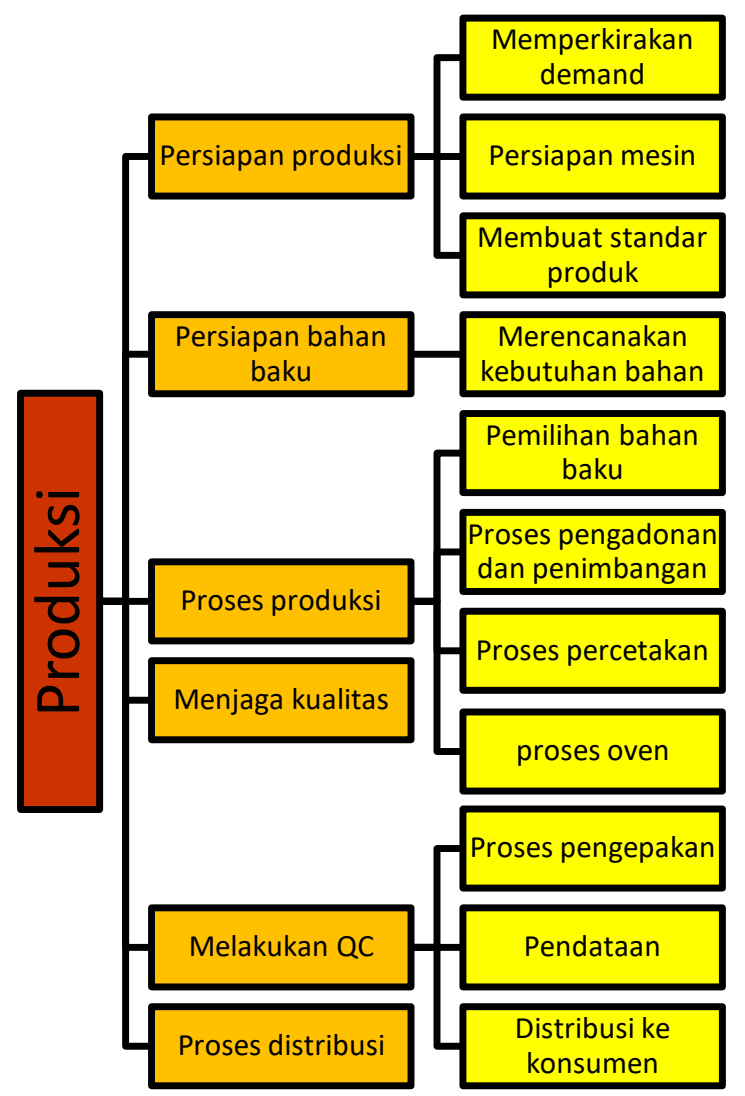

Gambar 2. Bagan Proses Produksi Bakery AICA

\section{Manajemen SDM dan pemasaran}

Bakery AICA ini terbilang laris di pasaran karena banyak yang memesan roti ini untuk berbagai kegiatan. Karena rasa roti yang di jual sesuai dengan selera pasar dan harganya pun terjangkau di kalangan masyarakat, sehingga para pembeli banyak berminat untuk membeli roti ini. Roti AICA ini terbuat dari bahan-bahan alami, rasanya enak, ekonomis hanya dengan membayar uang 7000 kita akan mendapat 2 potong roti. Roti ini di jual di sekitar tempat produksi dan melalui pesanan seperti di kampus, acara kantor, acara resepsi, acara seminar dan sebagainya.

Selain rasanya yang enak dan harganya yang terjangkau banyak masyarakat lainnya yang berminat memesan roti ini. AICA juga memberikan alamat dan juga nomor telepon, sehingga bagi yang ingin memesan dapat langsung menghubungi produksi roti tersebut. Penjualan roti ini juga di promosikan dengan cara memberikan jasa pengantaran roti sampai ke tempat pembeli, bebas biaya transportasi dengan pemesanan jumlah tertentu. Apalagi jaman sekarang ini, pembeli atau konsumen hanya ingin cara yang simple untuk melakukan pemesanan makanan untuk melengkapi makanan di acaranya dan menginginkan pesanan roti langsung diantar ke tempat tujuan, sehingga Bakery AICA ini melakukan pelayanan prima dengan mengantarkan roti sampai ke tempat konsumen dengan jumlah pemesanan tertentu. Hanya tinggal menelfon, roti pun siap untuk di antar alamat tempat tujuan. 
Karena sudah banyaknya peminat untuk membeli roti, ibu Sulistini selaku penanggungjawab dari Bakery AICA selalu melakukan mengontrol kualitas produk, dan juga bertanggungjawab semua pesanan Bakery AICA. Bisnis roti ini berkembang dengan cepat di kalangan masyarakat didaerah Kedungkandang. Karena ibu Sulistini dan seluruh bagian produksi bersunguh-sunguh dan tekun dalam menjalankan bisnis ini karena itu prospek pengembangannya pun sangat cepat maju. Diperlukan penambahan karyawan bagian produksi, sehingga dapat melayani pesanan dalam jumlah yang besar. Perencanaan sumber daya manusia (SDM) perlu dilakukan agar jalannya usaha lancar dan tujuan usaha dapat tercapai (Orvala et al., 2019). Pada umumnya setiap pemimpin usaha mengharapkan bawahanya atau karyawannya mempunyai kemauan, kemampuan, serta semangat tinggi untuk menyelesaikan semua tugas yang dibebankan kepadanya. Oleh karena itu diperlukan sorotan yang lebih banyak terhadap sumber daya manusia SDM) yang berada dalam usaha tersebut (Viky Hertia et al., 2018).

Pemasaran produk merupakan hal sangat penting dalam suatu usaha, semakin banyak volume penjualan produk maka produk tersebut memberikan keuntungan yang besar bagi suatu bisnis atau usaha. Untuk memperluas pemasaran dilakukan penjualan secara online dan penggunaan website juga dapat mempermudah pelanggan (customer) dalam melakukan pembelian dan pemesanan barang, karena lebih efisen dalam segi jarak dan waktu (Nofiani et al., 2019; Tambunan et al., 2019) (. Selanjutnya strategi pemasaran dengan mengaplikasikan bauran pemasaran (product, people, place, price, dan promotion). Dengan adanya variasi maupun diversifikasi produk roti, harga yang ditetapkan sesuai dengan kualitas produk, tempat yang strategis dan promosi yang tepat diharapkan mampu meningkatkan volume penjualan dan memperluas pasar (Hermawan, 2018; Rahmawati et al., 2019).

Pemasaran produk mitra selanjutnya akan dibantu untuk pembuatan serta pengelolaan sosial media dan akan dibuatkan brosur untuk lebih mempermudah konsumen mengetahui jenis-jenis roti serta harganya. Diharapkan dengan adanya sosial media dan brosur akan membatu untuk lebih meningkatkan penjualan dan memperluas jaringan pemasaran. Solusi yang ditawarkan yaitu adanya bimbingan manajemen Pemasaran melalui pelatihan pemasaran dengan memaksimalkan social media. Salah satunya menggunakan instagram. Pendampingan berkelanjutan dalam pengembangan usaha dilakukan dengan menganalisis setiap bidang manajemen dan melakukan perbaikan, salah satunya dengan melakukan perbaikan struktur organisasi atau pengelola AICA dan menambah jumlah karyawan bagian produksi. Serta Pendampingan Pengajuan P-IRT.

\section{HASIL DAN PEMBAHASAN}

Kegiatan pendampingan Bakery AICA PCA Kedungkandang Malang bertujuan untuk meningkatkan akses pasar dan pengembangan produksi Bakery AICA. Melalui kegiatan pendampingan ini diharapkan akan menghasilkan produk AICA yang berkualitas, cita rasa yang enak, dan produk tersebut dalam proses mendaftarkan merk dagang. Pendampingan pemasaran dengan melalui pelatihan yang dilakukan kepada beberapa orang untuk memaksimalkan sosial media. Sosial media yang digunakan adalah instagram dengan dasar bahwa banyak usaha sukses melalui instagram. Pembuatn instagram khususnya difokuskan untuk mempermudah calon konsumen mengenal setiap produk yang diproduksi serta memaksimalkan jaringan instagram untuk memasarkan produk-produk AICA. Pemilihan foto kue dan caption menjadi salah satu fokus pelatihan. Sehingga setiap foto yang diupload dapat dimaksimalkan dengan adanya caption-caption yang menarik.

Fokus pendampingan pengembang usaha juga pada pengelolaan dari sumber daya di AICA. Beberapa orang yang bekerja di AICA fokus juga dengan pekerjaan lainnya sehingga perlu adanya pembagian peran yang jelas antar pengelola. Pembuatan struktur organisasi dan pembagian jobdes perlu dilakukan. Dibutuhkan pula tambahan pekerjaan yang fokus pada produksi, sehingga bisa melakukan produksi setiap hari dan bisa memaksimalkan dari segi pemasaran jika ada admin khusus yang memegang sosial media yang dimiliki AICA. Perbaikan usaha yang berkaitan pemasaran dan sumber daya manusia juga harus didukung dengan produk yang kuat. Salah satu caranya dengan memberikan merk dagang. Namun penggunaan nama AICA telah dipatenkan oleh perusahaan lain sehingga merk dagang belum bisa digunakan. Salah satu yang bisa dimaksimalkan adalah pengenalan logo, sehingga diajukan paten logo dengan menggunakan profil perusahaan.

Dalam Kegiatan Pengabdian masyarakat melalui program pendampingan Bakery AICA PCA Kedungkandang Malang, tim pengabdian melakukan kegiatan dalam jangka panjang dapat memberikan nilai tambah ekonomi bagi amal usaha Muhammadiyah, sehingga menjadi usaha produktif yang dapat meningkatkan pendapatan di Bakery AICA dan meningkatkan pendapatan PCA Kedungkandang Malang. Perbaikan yang harus dilakukan diawal adalah perbaikan dari segi MSDM, karena beberapa hal sehingga 
pengelola dari Bakery AICA belum masif dalam pengelolaan usahan serta pemasaran. Sehingga dilakukan diskusi untuk pembagian kerja dan penyusunan ulang pengelola Bakery AICA. Dibutuhkan tambahan pekerja untuk mengelola serta membantu dalam pemasaran.

Perbaikan dari bidang pemasaran dilakukan dengan membuat instagram yang digunakan untuk menginformasikan terkait roti baru yang diciptakan atau roti-roti yang sudah dimiliki oleh bakery AICA. Pembuatan Instagram juga akan mempermudah konsumen untuk mengenal setiap jenis roti yang dijual oleh AICA. Bakery AICA dalam proses pembuatan merk dagang mengalami kendala karena persyaratan yang tidak dapat dilengkapi serta nama "AICA" sudah ada yang memiliki. Sehingga yang awalnya tim pengabdian akan membuat merk dagang, akhirnya berubah menjadi paten logo. Maka hasil dari pengabdian ini yaitu adanya P-IRT, Adanya Publikasi Ilmiah, dan Adanya draft untuk HKI Logo. Contoh produk yang dipasarkan oleh AICA adalah sebagai berikut:
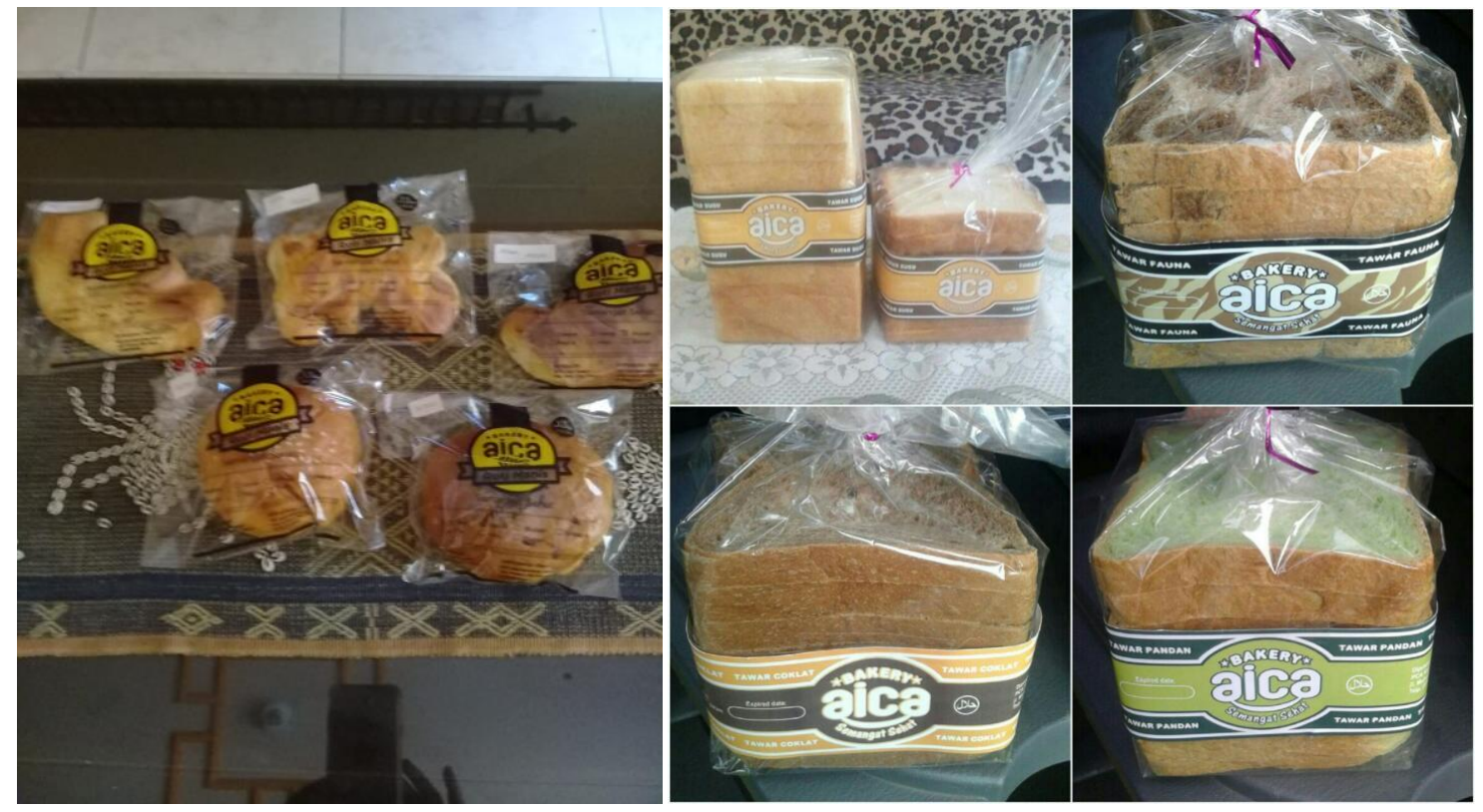

Gambar 3. Contoh Produk AICA

\section{KESIMPULAN DAN SARAN}

Hasil Kegiatan Pengabdian pengembangan bakery AICA ini meningkatkan ketrampilan pengelolaan manajemen usaha yang lebih professional mulai pengelolaan manajemen sumberdaya manusia dan manajemen pemasaran. Pemasaran bakery diperluas dengan menggunakan media sosial dan sumber daya manusia atau karyawan bagian produksi ditambah, sehingga Bakery AICA menjadi usaha yang lebih produktif. Melalui program pendampingan Bakery AICA PCA Kedungkandang dalam jangka panjang dapat memberikan nilai tambah ekonomi bagi amal usaha Muhammadiyah tersebut. Luaran program pengabdian adalah produk memperoleh P-IRT, Publikasi Ilmiah, dan draft untuk HKI Logo. Saran kegiatan pengabdian ini adalah diperlukan pendampingan intensif bagi mitra usaha sehingga nanti mitra usaha lebih mandiri dan produktif. Kegiatan ini dapat dilanjutkan dengan bermitra kelompok yang lebih professional dan mempunyai potensi pemasaran tingkat Nasional sehingga dapat digunakan sebagai kelanjutan pengusulan program pengabdian.

\section{UCAPAN TERIMA KASIH}

Ucapan terimakasih kami sampaikan untuk terselenggaranya program pengabdian kepada masyarakat atas pendanaan yang diberikan oleh Universitas Muhammadiyah Malang melalui dana Direktorat Penelitian dan Pengabdian Kepada Masyarakat (DPPM-UMM).

\section{REFERENSI}

Afridhal, M. (2017). Strategi Pengembangan Usaha Roti Tanjong Di Kecamatan Samalanga Kabupaten Bireuen. Journal of Chemical Information and Modeling, 53(9), 1689-1699. 
https://doi.org/10.1017/CBO9781107415324.004

Aini, N., \& Rifani, L. (2015). Pengembangan Desain Sistem Informasi Akuntansi Pada Usaha Kecil Dan Menengah Kampung Roti Surabaya. Seminar Nasional Sistem Informasi Indonesia, 2-3 Novemb(November), 509-524.

Azelia. (2015). Buku Resep Bogasari. Tersedia pada http://www.bogasari.com/, diakses pada tanggal 13 Februari 2019 Pukul 18.45

Buku Panduan Program Pengabdian Kepada Masyarakat Internal dan Artikel Ilmiah, UMM: 2018

Dewi, et al. (2015). Strategi Pengembangan Usaha Produksi Roti Bali Kencana Bakery, Denpasar Ni Putu Kiki Vrashinta Dewi 1, Ni Luh Putu Wrasiati 2 , I Ketut Satriawan 2 1. Jurnal Rekayasa Dan Manajemen Agroindustri, 3(4), 41-50.

Dwikurnia, T. (2016). Theodorus Indra Dwikurnia dan Ratih Indriyani. 4(1), 845-854.

Hermawan, H. (2018). Analisis Pengaruh Bauran Pemasaran Terhadap Keputusan, Kepuasan Dan Loyalitas Konsumen Dalam Pembelian Roti Ceria Di Jember. Jurnal Manajemen Dan Bisnis Indonesia, 3(2), 1-15. https://doi.org/10.17509/jaset.v3i2.8918

Khikmawati, E. (2018). Jurnal Riset Akuntansi dan Manjemen, Vol. 7, No. 1, Juni 2018. 7(1), 56-64.

Kraus, Ulrike dan Ruth Mader. (2004). The Book The World of Bread History. Arlington: U.S. Wheat Associated.

Lang, K., Massie, J., \& Ogi, I. (2015). Usaha Mikro Di Manado. 15(05), 646-655.

Nofiani, M. U., Lestari, U., \& Fatkhiyah, E. (2019). Jurnal Script Vol . 7 No . 2 Desember 2019 Pengembangan Sistem Informasi Penjualan Roti Maryam Berbasis Web Menggunakan Php Dan Mysql ( Studi Kasus: 'Arfa Bakery) Jurnal Script Vol . 7 No . 2 Desember 2019 E- ISSN : 23386313. 7(2), 194-202.

Nurdin, E. (2017). Jurnal mega aktiva. Jurnal Mega Aktiva, 6(April), 39-47.

Orvala, V., Yusiana, S., \& Ningrum, L. (2019). Analisa konsep usaha roti dalam perspektif manajemen sumber daya manusia. 3(3), 236-244.

Rahmawati, D., Handayani, R. D., \& Fauzzia, W. (2019). Pengembahang Pemasaran Produk Roti dan Pastry dengan Bauran Pemasaran 4P di Sari Good Bakery. Jurnal Abdimas BSI: Jurnal Pengabdian Kepada Masyarakat, 2(1), 233-243.

Tambunan, W., Amelia, T., Priyana, F. P., Studi, P., Industri, T., Teknik, F., Mulawarman, U., \& Pemasaran, S. (2019). Dan Menengah Manis Bakery. 5(1), 23-34.

Viky Hertia, E., Setyariningsih, E., \& Syamsul Hidayat, M. (2018). Analisa Strategi Pengembangan Ukm Mojosari Bakery Ditinjau Dari Aspek Pemasaran Dan Aspek Keuangan. 1-15.

Yola, M. dan nanda hardiyanti. (2019). 1 st Conference on Industrial Engineering and Halal Industries ( CIEHIS ) Kuliner Di Yogyakarta 1 st Conference on Industrial Engineering and Halal Industries ( CIEHIS ). 86-90. 
